\title{
Development of Improved Ciherang-Sub1 Having Tolerance to Anaerobic Germination Conditions
}

\author{
Anna Mariel U. Toledo ${ }^{1,2}$, John Carlos I. Ignacio ${ }^{1}$, Carlos Casal Jr. ${ }^{1}$, Zennia Jean Gonzaga ${ }^{1}$, Meryn S. Mendioro ${ }^{2}$, \\ Endang M. Septiningsih ${ }^{1}$ * \\ ${ }^{1}$ International Rice Research Institute, DAPO Box 7777, Metro Manila, Philippines \\ ${ }^{2}$ University of the Philippines, Los Banos, Laguna 4031, Philippines
}

\begin{abstract}
The increased severity and frequency of flooding is causing greater yield reductions in most rice-growing areas. To address this, popular cultivars were improved through introgression of SUB1, an FR13A-derived QTL conferring submergence tolerance at the vegetative stage, using marker-assisted backcrossing (MABC). Ciherang-Sub1, one of these improved near isogenic lines (NILs), showed significantly higher tolerance compared to the original cultivar while retaining its desirable agronomic qualities. However, due to the current shift to direct seeding, seed germination may also be adversely affected by flooding; thus the addition of major QTLs which can confer anaerobic germination (AG) tolerance will be highly beneficial. The AG tolerance QTL, qAG-9-2, also referred to as $A G 1$, derived from Khao Hlan On, a Myanmar landrace, has been introgressed into the elite cultivar IR64 to produce IR64-AG1. This research focused on the transfer of $A G 1$ to Ciherang-Sub1 via MABC, using IR64-AG1, a closely-related donor. Introgression of $A G 1$ and recovery of the Ciherang genome was done in two backcross generations followed by one generation of selfing. The use of a closely-related donor shortened the development period to two years which could have been further reduced if a larger $\mathrm{BC}_{1} \mathrm{~F}_{1}$ population had been used. Phenotypic evaluation showed that introgression of $A G 1$ significantly increased AG tolerance compared to Ciherang-Sub1, and that the newly developed Ciherang-Sub1+AG1 retained the submergence tolerance from SUB1. The approach is very promising for faster development of improved lines using closely-related cultivars or improved lines as donors for introducing key traits.
\end{abstract}

Keywords Rice (Oryza sativa L.), Anaerobic germination (AG) tolerance, Submergence tolerance, Direct seeded, Marker-assisted backcrossing (MABC)

\section{INTRODUCTION}

To address the projected population increase, the Food and Agriculture Organization of the United Nations (2009) predicted that global food production must rise by $70 \%$ by 2050. In developing countries, $80 \%$ of this increase is expected to result from greater yield and cropping intensities rather than from larger cropping areas. However, rice production continues to be hampered by numerous factors. In a study conducted in South Asia, flooding was identified as the third greatest stress which limits rice production (Widawsky and O'Toole 1990). Ram et al. (2002) estimated that at least $16 \%$ of rice growing areas worldwide are prone to flooding, and in South and Southeast Asia, more than 15 million hectares devoted to rainfed lowland rice are affected (Septiningsih et al. 2009). Furthermore, due to present day extreme weather conditions including the increase in the number and strength of monsoons, even other ecosystems (i.e. irrigated) could become susceptible to flooding.

Most rice varieties including the high-yielding varieties (HYVs) planted to the majority of Asian rice production regions cannot survive flash floods or complete submergence of more than a few days (Ismail et al. 2010). They also cannot germinate under anoxic or hypoxic conditions (Angaji et al. 2010; Baltazar et al. 2014). Except for upland rice, flooding can affect all ecosystems at different times during the cropping season; thus tolerance to submergence in all growth stages of rice would have a great impact on

Received April 26, 2015; Revised May 6, 2015; Accepted May 6, 2015; Published June 30, 2015

*Corresponding author Endang M. Septiningsih, e.septiningsih@irri.org, Tel: +63-2-580-5600 , Fax: +63-2-580-5699 
increasing crop survival and consequently grain yield. Most farmers in these areas plant either HYVs with good agronomic traits that are susceptible to flooding or moderately tolerant cultivars that have moderate to low yield. Hence, the development of cultivars with high tolerance and good agronomic traits is essential.

This study focused on tolerance to anaerobic germination (AG) and flash floods (submergence) which are two of the four general types of flooding stress described by Mackill et al. (2010). AG involves flooding during early crop establishment particularly after direct seeding which leads to submergence of seeds prior to or during germination. The shift to direct seeding has been occurring all over Asia mainly due to labor scarcity (Pandey and Velasco 2002). However, this method is also more prone to crop establishment problems due to higher sensitivity of seeds to stress (Naklang et al. 1996; Naklang 1997). On the other hand, flash flooding results in the complete submergence of plants for two weeks or more (Mackill et al. 2010). In an attempt to regain their normal aerobic metabolism and photosynthetic abilities, most cultivars elongate (Jackson and Ram 2003) but this often leads to depletion of carbohydrate reserves.

Cultivars with tolerance to different flooding stresses have been introduced in the past, but farmers have been wary of adopting new cultivars with traits which differ from those of varieties they traditionally grow as seen in the submergence-tolerant breeding lines developed as early as the 1980s (Mackill 2006). Thus, the current approach is to improve the widely grown cultivars or "mega varieties" through introgression of the trait which involves the transfer of the quantitative trait loci (QTLs) or gene(s) responsible for a trait from one variety (donor parent) to another (recurrent parent) while retaining the genetic background of the recurrent parent. The incorporation of a single gene or a QTL with large effects would commonly take at least four backcross generations.

To fast track this process, marker-assisted backcrossing (MABC) which typically involves detecting the trait of interest using specific gene-based markers and/or markers tightly-linked to the target region in the genome (foreground selection and recombinant selection, respectively) and evaluation of the rest of the genome for accelerated recovery of the recurrent parent genotype (background selection) may be used (Collard and Mackill 2008; Neeraja et al. 2007). This has proven successful in numerous rice breeding programs to introgress genes or QTLs for resistance to biotic stresses, tolerance to abiotic stresses, and better grain quality (Jena and Mackill 2008).

The QTLs responsible for a significant percentage of variation in submergence tolerance (SUB1) and anaerobic germination tolerance ( $q A G-9-2$ or $A G 1)$ in rice have been previously identified. The largest effect QTL identified for submergence tolerance, $S U B 1$, accounts for about $69 \%$ of the variation (Xu and Mackill 1996), while $q A G-9-2$ for anaerobic germination tolerance accounts for about $33 \%$ of the variation (Angaji et al. 2010). The underlying genes for both QTLs have also been identified and characterized (Xu et al. 2006; unpublished data). SUB1 introgressed cultivars have shown significantly higher tolerance while maintaining the desired agronomic characteristics. Some of these have already been released to farmers while others are still in advanced or earlier stages of phenotypic evaluation (Iftekharuddaula et al. 2011; Mackill et al. 2012; Neeraja et al. 2007; Septiningsih et al. 2009, 2013a, 2015; Singh et al. 2009).

According to Mackill (2004), a viable and fast strategy for the transfer of defined QTLs could allow combining of tolerance to multiple stresses. Several studies have reported the effective use of MABC in pyramiding QTLs for more durable pest and disease resistance, combined tolerance to multiple abiotic stresses, and improved grain quality and yield (Ashikari and Matsuoka 2006; Shinada et al. 2004; Wang et al. 2012). In this study, SSR markers and gene-based markers were used to improve an Indonesian mega variety, Ciherang, through combined introgression of the QTL for tolerance to submergence (SUB1) (Septiningsih et al. 2015) and a major QTL for tolerance to AG, $q A G-9-2$, derived from Myanmar's landrace, Khao Hlan On (Angaji et al. 2010).

\section{MATERIALS AND METHODS}

\section{Plant materials and crossing scheme}

The "mega variety" selected for improvement was 
Ciherang, a widely grown Indonesian cultivar developed from multiple variety crosses (MVC) including IR64 (International Rice Information System 2009). Similar to IR64 which is popular in the Philippines, Ciherang also possesses good agronomic characteristics (Mackill et al. 2010) but it seems to be more appropriate in the dry season due to its intolerance to flooding (Sumarno and Sutisna 2010). An upgraded version of this variety carrying the SUB1 QTL, namely Ciherang-Sub1, has been developed (Septiningsih et al. 2015).

Near isogenic lines (NILs) of the closely-related cultivar IR64 were used as immediate sources of the QTLs for submergence and AG tolerance. IR07F102 (IR64-Sub1), a submergence tolerant line with the FR13A-derived Sub1 allele (Septiningsih et al. 2009) was crossed to an anaerobic germination tolerant line, IR93312-30-101-20-3-66-6-14 (IR64-AG1) containing the KHO-derived tolerance allele of the $q A G-9-2$ or $A G l$ QTL. After two selfing generations, the $F_{2: 3}$ progenies of the best $F_{2}$ plants from the cross of IR64-AG1 and IR64-Sub1 were used for the initial crossing with IR09F436 (Ciherang-Sub1). IR64-Sub1 and IR64-AG1 were developed through two and four backcross generations, respectively, whereas Ciherang-Sub1 was developed using a single backcross generation with IR64Sub1 as the donor for submergence tolerance (Septiningsih et al. 2009, 2015).

Based on foreground and background genotyping, desirable plants from the $F_{1}$ population produced from the three-way cross (IR64-Sub1/IR64-AG1//Ciherang-Sub1) were chosen and backcrossed to Ciherang-Sub1. All selected plants from the resulting $\mathrm{BC}_{1} \mathrm{~F}_{1}$ were backcrossed to Ciherang-Sub1 to produce $\mathrm{BC}_{2} \mathrm{~F}_{1}$. Plants selected from the $\mathrm{BC}_{2} \mathrm{~F}_{1}$ were selfed producing the $\mathrm{BC}_{2} \mathrm{~F}_{2}$. From these, plants with successful introgression of $S U B 1$ and $A G 1$ tolerant alleles, and maximum recovery of the Ciherang background were selected and designated as CiherangSub1+AG1. All plantings and crosses were done at the International Rice Reserach Institute (IRRI) using standard practices.

\section{Markers for foreground and background selection}

Foreground selection was done to detect the presence of the $S U B 1$ tolerant allele and the $A G 1$ tolerant allele. For the $S U B 1$ locus, RM8300, an SSR marker found approximately $330 \mathrm{~kb}$ downstream of $S U B 1 A$, and ART5, an Indel marker found within $S U B 1 C$ were used (Neeraja et al. 2007; Septiningsih et al. 2009). For the $A G 1$ locus, two to three markers were used depending on the population. For population one (IR64-AG1c: IR93312-30-101-20-3-66-6-14), markers used were TPP_GE5 and HPP400_410_3, while for population two (IR64-AG1: IR93312-30-101-20-1364-13) markers used were TPP_GE5, Drebups6bp and Drebdws4bp (unpublished data). During background selection for genetic similarity to Ciherang, 26 polymorphic SSR markers spaced evenly in the polymorphic regions between IR64 and Ciherang were used (Supplementary Table 1). This number of polymorphic markers proved to be sufficient since this same set was used to develop Ciherang-Sub1 which was similar to the original cultivar in agronomic, grain and yield traits except for improved submergence tolerance (Septiningsih et al. 2015).

\section{Molecular marker analysis}

Genomic DNA was extracted from two-week old seedlings following the protocol for microscale rice DNA isolation for PCR analysis by Zheng et al. (1995) with slight modifications. A 96-well PCR plate was used and the PCR cocktail was prepared using a previously described protocol (Septiningsih et al. 2012). Each plate which contained samples from the population, as well as three checks (IR64, Ciherang-Sub1 and Khao Hlan On), was loaded into a G-Storm thermal cycler (G-Storm Ltd., UK). After initial denaturation at $94^{\circ} \mathrm{C}$ for $5 \mathrm{~min}$, a cycle consisting of 45 -s denaturation at $94^{\circ} \mathrm{C}, 45$-s annealing at 55 or $60^{\circ} \mathrm{C}$ (depending on the primer used), and 60-s extension at $72^{\circ} \mathrm{C}$ was repeated 35 times, ending with final extension at $72^{\circ} \mathrm{C}$ for $5 \mathrm{~min}$. Amplified DNA fragments were mixed with bromophenol blue gel loading dye and were resolved by electrophoresis on $8 \%$ polyacrylamide gel at 100 volts for 1.5 to 2.5 hours depending on the expected fragment size (CBS Scientific Co. Inc., CA, USA). The gel was stained in $0.0001 \%$ SYBR Safe DNA gel stain solution (Invitrogen) and was viewed using a gel documentation system (Alpha Innotech) for allele scoring. 


\section{Plant selection}

At the $\mathrm{F}_{1}, \mathrm{BC}_{1} \mathrm{~F}_{1}$, and $\mathrm{BC}_{2} \mathrm{~F}_{1}$ generations, initial foreground selection was for plants homozygous for the SUB1 tolerant allele and those heterozygous for the $A G 1$ tolerant allele. These plants with the desired foreground were then subjected to background selection. In the $F_{1}$ generation, background selection was done to eliminate those which were not heterozygous for the alleles from Ciherang and IR64. In the $\mathrm{BC}_{1} \mathrm{~F}_{1}$, and $\mathrm{BC}_{2} \mathrm{~F}_{1}$ populations, plants with the most number of background loci similar to Ciherang were chosen. SSR markers which corresponded to loci that were fixed (homozygous for the Ciherang allele) in the previous generation were no longer included for the marker analysis of the next generation. However, all SSR markers were used for genotypic confirmation of selected plants. In the $\mathrm{BC}_{2} \mathrm{~F}_{2}$ generation, foreground selection identified plants which were homozygous for both the $S U B 1$ and $A G 1$ tolerant alleles. From these, plants which shared more than $99 \%$ background similarity with Ciherang were chosen for further evaluation as the improved cultivar Ciherang- Sub1+AG1.

\section{Evaluation of Ciherang-Sub1+AG1 material}

Phenotyping for anaerobic germination tolerance was conducted at the $\mathrm{BC}_{1} \mathrm{~F}_{2}$ generation. Closely linked- markers were used to select for plants which were negative for the $A G 1$ tolerant allele and plants which were homozygous for the $A G 1$ tolerant allele. AG tolerance phenotyping was done in the NG-01-01 screen house at IRRI using standard protocols (Septiningsih et al. 2013b). After breaking dormancy for five days, $\mathrm{BC}_{1} \mathrm{~F}_{3}$ seeds of IR64-Sub1/IR64-AG1// Ciherang-Sub1 and the checks Ciherang, Ciherang-Sub1 and IR42 were sown in plastic seedling trays. The entries were randomly arranged in two replicates using Alpha Lattice Design. For each replicate, two rows of 15 boxes each were allotted for each sample, while the checks appeared twice. To lessen possible experimental errors, rows in between entries and the outermost boxes of the tray were left empty. Each box was first half-filled with fine soil; then one seed was placed and covered with $1 \mathrm{~cm}$ of fine soil. The trays were placed in concrete benches and submerged under $10 \mathrm{~cm}$ of water for 21 days. Scoring for survival was done at 16 and 21 days after sowing (DAS). Data analysis was done using Statistical Tools for Agricultural Research (STAR) software (http://bbi.irri.org/products). Analysis of Variance (ANOVA) $(\alpha=0.05)$ and pairwise mean comparison using Tukey's Honest Significant Difference (HSD) Test ( $\alpha=0.05)$ were performed.

Thirty seeds from each entry were also allowed to germinate in petri dishes lined with moist filter paper to check for germination rate under aerobic conditions. Seeds were incubated for seven days at $30^{\circ} \mathrm{C}$ and scoring was done. Plants which had a germination rate lower than $80 \%$ in the control setup were excluded from the analysis.

Submergence tolerance screening was done in the BG-02 outdoor tank at IRRI. Thirty pre-germinated seeds each for Ciherang-Sub1+AG1 were germinated along with the checks IR42, Ciherang, Ciherang-Sub1, IR64-21, IR64-Sub1+AG1, KHO, and FR13A in rows within $20 \mathrm{~cm}$ $\times 15 \mathrm{~cm} \times 10 \mathrm{~cm}$ plastic trays. The cultivars were randomly arranged in two replicates (trays) using Alpha Lattice Design. When seedlings reached 14 days old, the trays were placed in a concrete tank and were completely submerged in water at a depth of approximately $1.5 \mathrm{~m}$. When the susceptible check showed sufficient damage, the trays were de-submerged. The survival of plants was scored at 7, 14 and 21 days after desubmergence, and percentage survival was computed. Data was analyzed using the STAR software (http://bbi.irri.org/products), and ANOVA $(a=0.05)$ and pairwise mean comparison using Tukey's HSD Test $(\alpha=0.05)$ were done.

Ciherang-Sub1+AG1, IR64-Sub1+AG1, along with five other checks (i.e. Ciherang, Ciherang-Sub1, IR64, IR64-AG1 and NSIC Rc222, a high yielding rice variety recently released in the Philippines) were evaluated in IRRI field station in 2015 dry season. A randomized complete block design was used with four replicates, plot size of 11.6 $\mathrm{m}^{2}, 20 \mathrm{~cm}$ x $20 \mathrm{~cm}$ planting distance. Seeds were sown in the seed bed and 21-day old seedlings were transplanted in the plots. Fertilizer and crop protection management were applied as recommended. Days to $50 \%$ flowering was recorded. Plant height and tiller count was gathered from five randomly selected plants inside the plot at maturity. The net plot size harvested was $5 \mathrm{~m}^{2}$ or 125 plants inside the plot. Yield calculation was adjusted according to the 
corresponding moisture content. Data were analyzed using PB Tools 1.4 (http://bbi.irri.org/products), and the least significant difference test at $P<0.05\left(\mathrm{LSD}_{0.05}\right)$ and broad-sense heritability $(\mathrm{H})$ were calculated.

\section{RESULTS}

\section{Development of Ciherang-Sub1+AG1}

In the development of Ciherang-Sub1+AG1 (Fig. 1), foreground markers for both SUB1 (RM8300 and ART5) and $A G 1$ (TPP_GE5 and HPP400_410_3 for population one; TPP_GE5, Drebdws4bp, and Drebups6bp for population two) were used to narrow down the plants prior to background selection using the 26 polymorphic SSR markers. Foreground selection for the $S U B 1$ locus in the $\mathrm{F}_{1}$ progeny revealed that the ratio of homozygous tolerant individuals (B) and the heterozygotes (H) approximated the expected ratio of 50:50 (Fig. 2A). However, genotyping also detected a few products of selfing which were

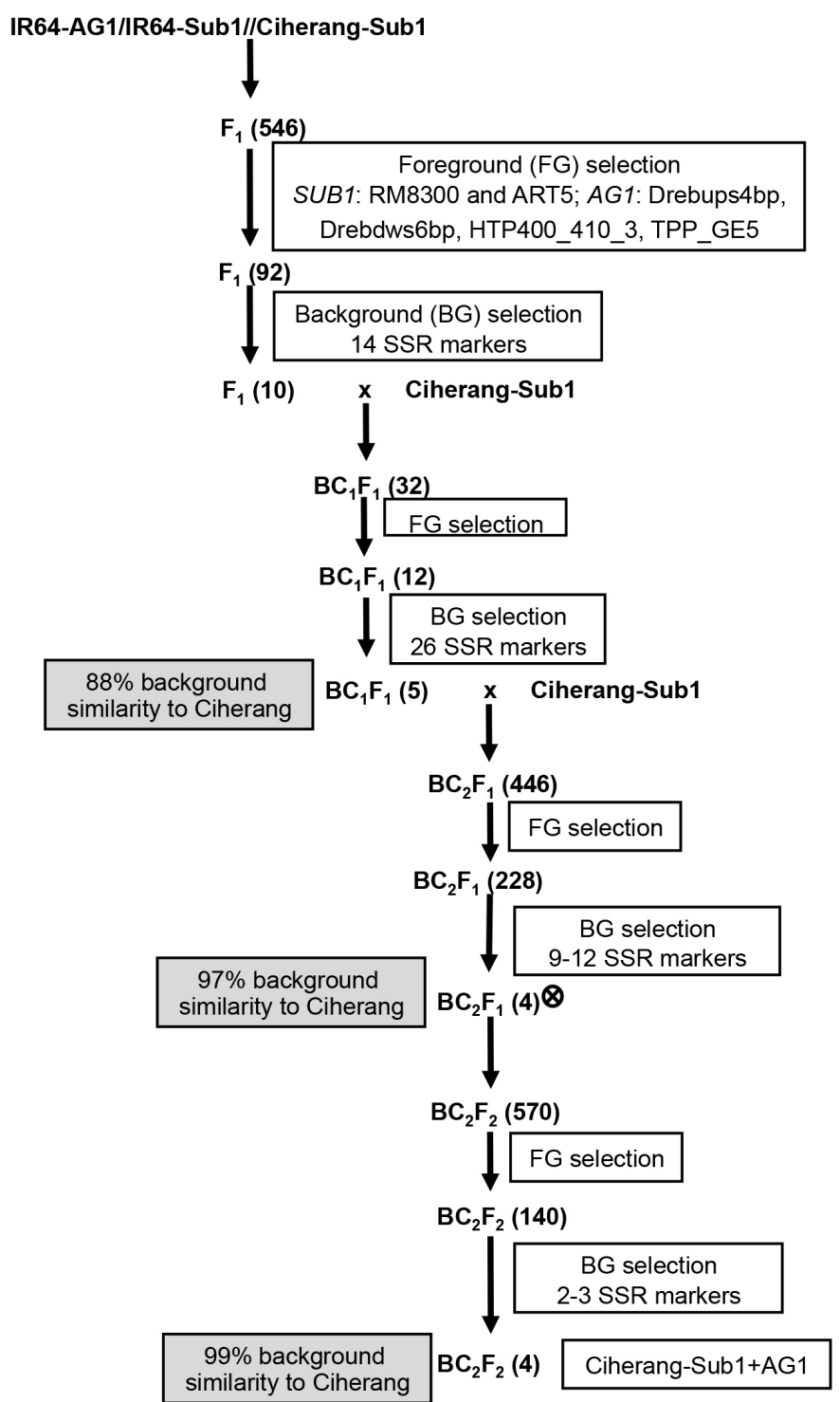

Fig. 1. Breeding scheme for the development of Ciherang-Sub1+AG1 from IR64-Sub1/IR64-AG1//Ciherang-Sub1. The shaded boxes contain the percent recovery of the Ciherang background for each generation. The number of plants selected after each round of genotyping is enclosed in the parentheses. 
homozygous for the intolerant allele (A). The same segregation ratio was also seen in the $A G 1$ locus for the plants that were homozygous for the intolerant allele (A) and the heterozygotes $(\mathrm{H})$. From the 542 plants, 72 which were homozygous for the SUB1 tolerant allele and heterozygous for $A G 1$ were selected. To increase the chances for plants with favorable background to be selected, some plants which were heterozygous for both $A G 1$ and SUB1 loci were randomly selected to come up with 92 for background selection (Fig. 1). Finally, seven plants which were heterozygous for all background loci except the tip of chromosome $9(1 \mathrm{Mb})$ which was fixed for the $S U B 1$ tolerant allele were selected for backcrossing to Ciherang-Sub1. These plants were homozygous for the tolerant $S U B 1$ allele and heterozygous for the tolerant $A G 1$ allele, except for one which was heterozygous for both.

Thirty-two $\mathrm{BC}_{1} \mathrm{~F}_{1}$ plants were subjected to foreground selection and 12 plants which were heterozygous at the $A G 1$ locus and were either homozygous or heterozygous for the tolerant allele at the SUB1 locus were subjected to background genotyping using the 26 SSR markers. Plants with more than $50 \%$ of these loci fixed as similar to Ciherang were chosen for backcrossing to Ciherang-Sub1 (Supplementary Fig. 1). Of the five plants selected, four were fixed at the SUB1 locus (23-1-25-1, 23-1-25-2, 23-1-25-3, and 30-2-27-1) and one (42-11-22-4) was not.

Foreground selection was done on $446 \mathrm{BC}_{2} \mathrm{~F}_{1}$ plants using the same process for the $\mathrm{BC}_{1} \mathrm{~F}_{1}$ where 228 were chosen for background genotyping using 9-12 markers representing the previously heterozygous loci in the respective $\mathrm{BC}_{1} \mathrm{~F}_{1}$ parents. Background genotyping revealed that eight plants were fixed as similar to Ciherang in all but 2-3 heterozygous background loci. After confirmation of foreground genotyping, four of these (23-1-25-3-52, 30-2-27-1-85, 30-2-27-1-103 and 30-2-27-1-109) were selfed to fix the remaining heterozygous background loci as well as the $A G 1$ locus.

A total of $570 \mathrm{BC}_{2} \mathrm{~F}_{2}$ plants were grown and subjected to foreground selection for plants which were fixed at both loci with the tolerant alleles. A total of 140 plants were selected and genotyping was done using the remaining previously heterozygous background markers. Plants which were fixed as similar to Ciherang in all loci except for the presence of the tolerant allele for both $A G 1$ and SUB1 were identified. DNA was then re-extracted from these plants and genotyping was repeated for the foreground as well as all 26 background loci. Confirmation revealed that the best four plants (1-109-116, 1-109-136, 1-103-10,

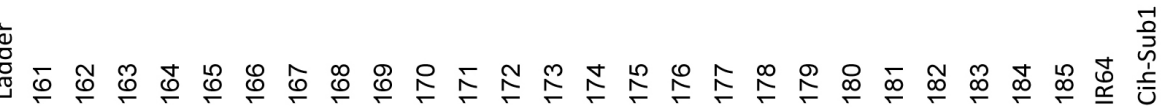

(A)
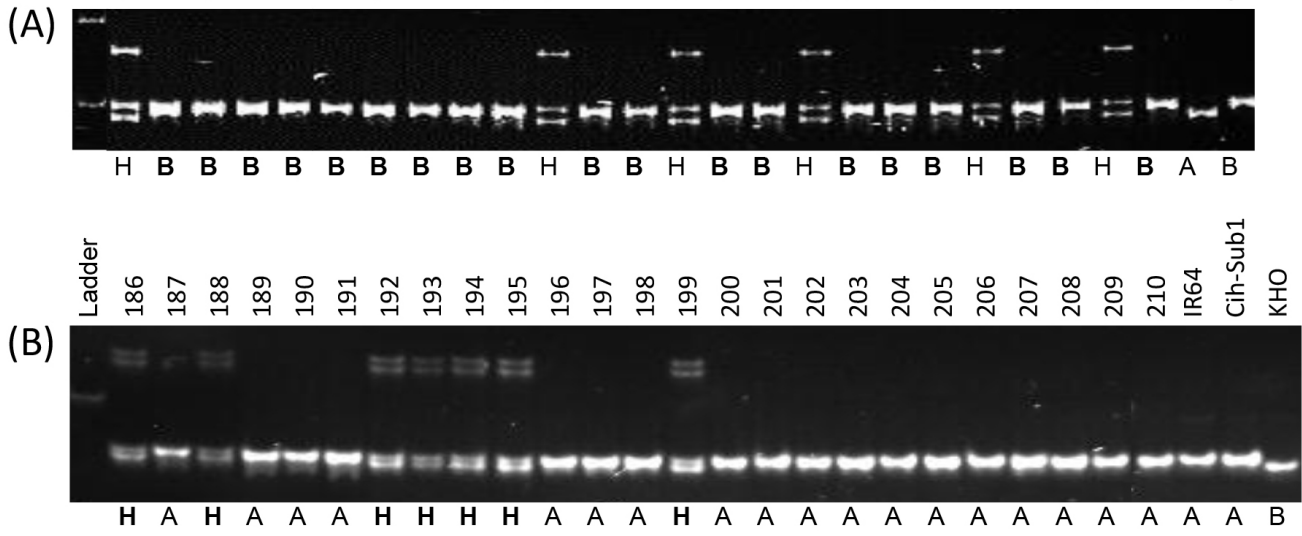

Fig. 2. Sample foreground selection of $F_{1}$ plants from the cross of IR64-Sub1/IR64-AG1//Ciherang-Sub1. (A) PCR amplification was done using RM8300 which is tightly linked to the SUB1 locus; the band from IR64 (intolerant allele) was scored as A, the band from Ciherang-Sub1 (tolerant allele) as B, and the heterozygote as H. (B) PCR amplification was performed using Drebdws4bp which is tightly linked to the $A G 1$ locus; the band from the intolerant, recurrent parent (Ciherang-Sub1) was scored as A, the tolerant $A G 1$ allele based on KHO was $\mathrm{B}$, and the heterozygote was H. Letters in bold represent the genotype selected for in each locus. 
and 1-85-174) were homozygous for the tolerant allele at the $A G 1$ and SUB1 loci. These were similar to CiherangSub1 at all background loci except one which was fixed as similar to IR64 instead. This locus represented by marker RM524 was located on $12.9 \mathrm{Mb}$ on chromosome 9. However, the next marker which is less than $0.5 \mathrm{Mb}$ from RM524 shows that the adjacent region is already conserved between the two cultivars. Since this region represented less than $1 \%$ of the genome and the introgression came from another elite cultivar IR64, these plants were subjected to phenotypic confirmation for $\mathrm{AG}$ tolerance and submergence tolerance as the improved Ciherang-Sub1+AG1.

\section{Phenotypic confirmation of AG tolerance}

The mean survival rate for the $\mathrm{BC}_{1} \mathrm{~F}_{3}$ plants at $21 \mathrm{DAS}$ is presented in Fig. 3A, in comparison with the checks. IR42 and Ciherang which both do not have the $A G 1$ tolerant allele had mean survival rates of $0.00 \%$ and $8.33 \%$, respectively. These were not significantly different from the performance of the AG- entries without the $A G 1$ tolerant allele $(9.44 \%)$ at $\alpha=0.05$. On the otherhand, $\mathrm{AG}^{+}$ entries with $A G 1$ tolerant allele had a mean survival rate of
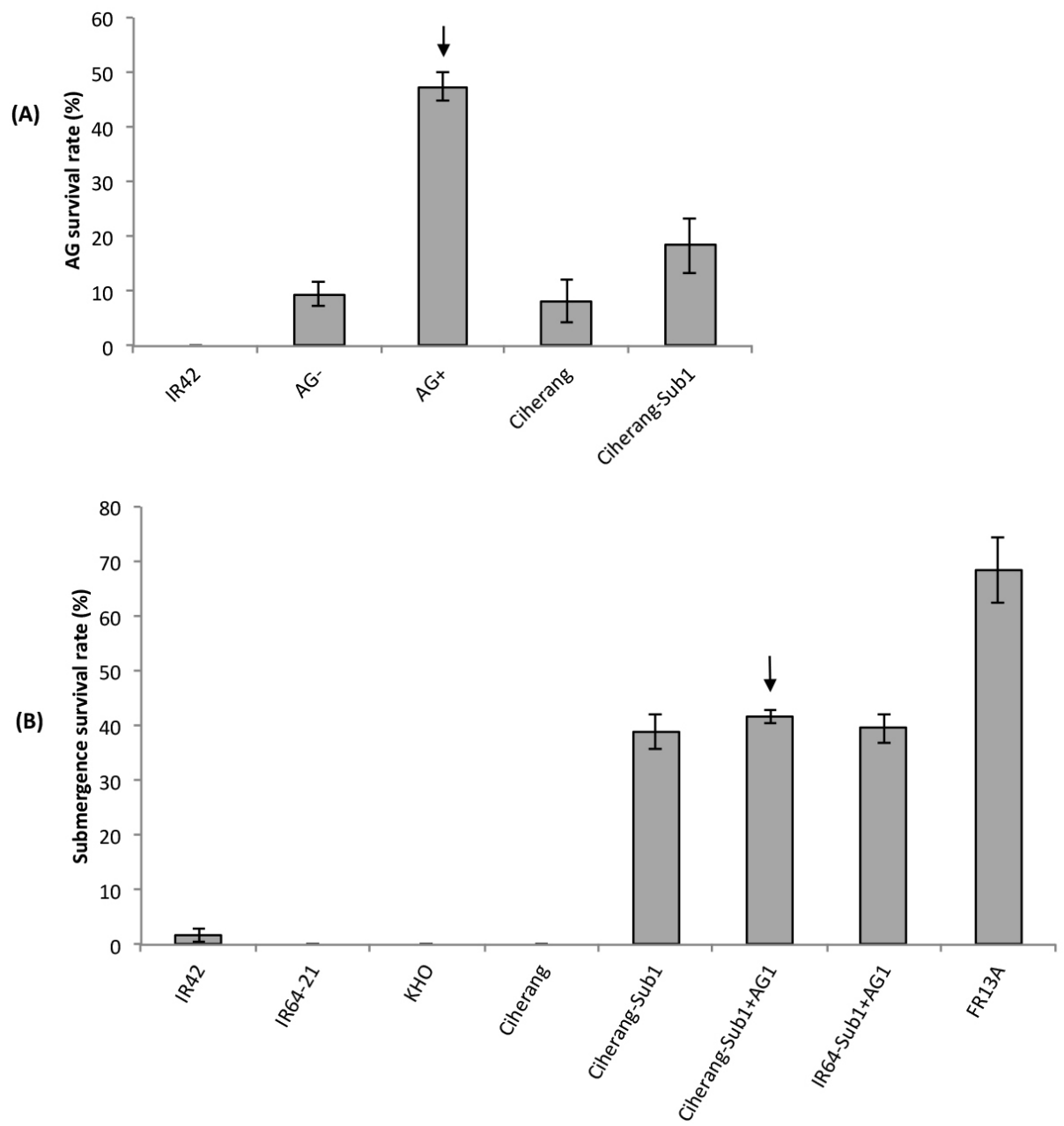

Fig. 3. Phenotypic evaluation of Ciherang-Sub1+AG1 $\mathrm{BC}_{1} \mathrm{~F}_{3}$ plants for anaerobic germination tolerance and $\mathrm{BC}_{2} \mathrm{~F}_{3}$ plants for submergence tolerance. (A) The figure contains the mean survival rate (\%) of lines with the $A G 1$ tolerant allele $(\mathrm{AG}+)$ and those without $\left(\mathrm{AG}^{-}\right)$compared with the checks, IR42, Ciherang and Ciherang-Sub1, after submergence for 21 days during germination. (B) The figure shows the mean survival rate (\%) of Ciherang-Sub1+AG1 after 34 days of submergence and 21 days of recovery. Data for intolerant checks, IR64, IR42, Ciherang, and KHO, and tolerant checks, Ciherang-Sub1, IR64-Sub1+AG1 and KHO, are also included. The vertical bars in both figures represent \pm S.E. 
$47.29 \%$ which was significantly higher compared to the original Ciherang as well as the NIL, Ciherang-Sub1. Though maximum recovery of the Ciherang background has not yet been attained in the $\mathrm{BC}_{1} \mathrm{~F}_{3}$ plants, successful introgression of the tolerant $A G 1$ allele significantly improved the survival rate under anaerobic germination.

\section{Phenotypic confirmation of submergence tolerance}

The mean percent survival of the Ciherang-Sub1+AG1 $\mathrm{BC}_{2} \mathrm{~F}_{\mathrm{n}}$ plant after 34 days of submergence was computed at 7,14 , and 21 days after desubmergence. The data after 21 days of recovery are presented in Fig. 3B. Susceptible varieties Ciherang, IR42, IR64-21 and KHO showed $0.00-1.67 \%$ survival whereas the tolerant check, FR13A, which had the tolerant $S U B 1$ allele exhibited $68.46 \%$ survival. The NILs introgressed with the SUB1 allele, IR64-Sub1+AG1 and Ciherang-Sub1, and the newly developed Ciherang-Sub1+AG1 showed comparative results at $39.52 \%, 38.91 \%$ and $41.67 \%$, respectively. Statistical analysis using Tukey's HSD test $(\alpha=0.05)$ showed that introgression of $S U B 1$ significantly improved the plant's tolerance with approximately $40 \%$ higher survival compared to the original parents, but the survival rate was significantly lower compared to FR13A, the original SUB1 donor.

\section{Evaluation of yield and several key agronomic traits}

The yield of Ciherang-Sub1+AG1 was significantly higher than that of Ciherang (Table 1). However there were no significance differences among IR64-Sub1+AG1, IR64-AG1 and IR64 for yield, plant height and days to 50\% flowering. There were no significant differences observed among all lines for tiller number. However, Ciherang Sub1+AG1 and Ciherang-Sub1 were significantly taller than Ciherang, and Ciherang-Sub1+AG1 flowered significantly later than Ciherang and Ciherang-Sub1. Heritability for all traits measured was high (Table 1).

\section{DISCUSSION}

MABC was used to introgress the QTL for tolerance to anaerobic germination $(A G l)$ to the previously developed Ciherang-Sub1 (Septiningsih et al. 2015) with the use of IR64 NILs containing $S U B 1$ or $A G 1$ as donors in order to produce an improved cultivar containing tolerance to both submergence and AG. The use of a closely-related cultivar rather than the original landraces reduced the period needed to two backcross generations followed by one generation of selfing. MABC was done using SSR and Indel markers for the $S U B 1$ and $A G 1$ loci (foreground

Table 1. Predicted mean plant height (PH), 50\% days to flowering (DTF), number of productive tillers (TN), and adjusted yield (Yield) of Ciherang-Sub1+AG1, IR64-Sub1+AG1, and their controls in the IRRI field in 2015 dry season. Data are averages from four replications.

\begin{tabular}{|c|c|c|c|c|c|}
\hline Entries & IR\# designation & $\begin{array}{l}\mathrm{PH}^{\mathrm{z})} \\
(\mathrm{cm})\end{array}$ & $\begin{array}{c}\mathrm{DTF}^{\mathrm{y})} \\
\text { (d) }\end{array}$ & $\mathrm{TN}^{\mathrm{x})}$ & $\begin{array}{c}\text { Yield } \\
(\mathrm{kg} / \mathrm{ha})\end{array}$ \\
\hline IR64 & IR64 & 86.67 & 87.06 & 16.86 & 5419.45 \\
\hline IR64-AG1 & IR $93312-30-101-20-3-66-6$ & 84.13 & 85.84 & 15.68 & 5494.97 \\
\hline IR64-Sub1+AG1 & IR 97703-468-21-39 & 85.06 & 86.32 & 15.68 & 5308.34 \\
\hline Ciherang & NA & 87.82 & 90.98 & 13.52 & 5127.97 \\
\hline Ciherang-Sub1 & IR87424-177-173 (IR09F436) & 93.59 & 92.20 & 12.93 & 5765.6 \\
\hline Ciherang-Sub1+AG1 & IR108353-27-1-85-174 & 92.67 & 97.10 & 12.34 & 5948.79 \\
\hline NSIC Rc222 & IRRI154 & 91.05 & 90.24 & 14.5 & 5773.27 \\
\hline$L S D(0.05)$ & & 3.13 & 1.64 & 2.70 & 644.5 \\
\hline$H$ & & 0.92 & 0.98 & 0.79 & 0.69 \\
\hline
\end{tabular}


selection) and 26 polymorphic SSR markers (background selection). For each generation of selection, plants were chosen for the presence of tolerant alleles of $A G 1$ and $S U B 1$, as well as maximum recovery of the Ciherang genome.

Results showed that two backcross generations followed by selfing were enough to develop the improved CiherangSub1+AG1 as long as the source of the tolerance is a closely-related cultivar like IR64 with high genomic similarity $(76 \%)$ despite a small population for the $\mathrm{BC}_{1} \mathrm{~F}_{1}$ for selection. It is possible to shorten the process to a single backcross provided that the $\mathrm{BC}_{1} \mathrm{~F}_{1}$ and $\mathrm{BC}_{1} \mathrm{~F}_{2}$ populations consisted of around 400 individuals or more as shown in a study by Septiningsih et al. (2015). Though their study involved introgression of a single QTL, it may be possible to do the same with two QTLs such as in this study since plants fixed for $S U B 1$ may be identified as early as in the $\mathrm{F}_{1}$ generation. This would mean that subsequent foreground selection would be for $A G 1$ alone and recovery of the background from Ciherang.

Phenotypic evaluation for tolerance to AG and submergence was done on Ciherang-Sub1+AG1 $\mathrm{BC}_{1} \mathrm{~F}_{3}$ and $\mathrm{BC}_{2} \mathrm{~F}_{3}$ (fixed) plants, respectively, in greenhouse experiments. AG tolerance phenotyping showed that mean percent survival at 21 DAS for plants introgressed with $A G 1$ was significantly higher compared to Ciherang and CiherangSub1 at 5\% level of significance. On the other hand, plants which did not contain $A G l$ had comparable germination and survival rates with the original Ciherang cultivar. For submergence tolerance phenotyping, the mean percent survival was computed after 34 days of submergence followed by 21 days of recovery. Ciherang-Sub1+AG1 exhibited a significantly higher survival rate with $40 \%$ improvement compared to susceptible varieties Ciherang, IR42, IR64-21 and KHO. The NILs introgressed with the SUB1 allele, IR64-Sub1+AG1 and Ciherang-Sub1, showed statistically similar results with the newly developed Ciherang-Sub1+AG1; although, the survival rate was significantly lower compared to FR13A, the original SUB1 donor. This difference in the degree of tolerance might be due to additional submergence tolerant QTL(s) in FR13A. Based on previous field trials for Ciherang-Sub1, the action of the $S U B 1$ gene did not seem to be negatively affected by the Ciherang background (Septiningsih et al. 2015). Overall, the results of this current study show that successful introgression of $S U B 1$ and $A G 1$ significantly improved the response of Ciherang to these two stresses and that the presence of both traits appears compatible, even though they have almost opposite mechanisms of tolerance. This might be due to the different stages when $S U B 1$ and $A G 1$ are expressed. In this case, SUB1 is expressed at early seedling stage up to panicle initiation while $A G 1$ is expressed during germination and very early growth (Xu et al. 2006; unpublished data).

Preliminary evaluation in the IRRI field station showed that there were no significant differences between IR64Sub1+AG1 and IR64-AG1 with the original line (i.e. IR64), in terms of yield and several key agronomic traits evaluated under normal conditions (Table 1). However, preliminary field evaluation showed that Ciherang-Sub1+ AG1 had significantly higher yield compared to Ciherang. This may be due to the significantly longer duration of flowering time, and consequently maturity of CiherangSub1+AG1, as seen in Table 1. Ciherang-Sub1+AG1 therefore would have more time to accumulate photosynthates that would be available for conversion to grain in comparison to Ciherang. Although in the IRRI field Ciherang-Sub1+AG1 and Ciherang-Sub1 were significantly taller than Ciherang, our extensive evaluation in multi-location trials demonstrated that Ciherang-Sub1 is similar to Ciherang (Septiningsih et al. 2015). These preliminary results showed that there is no yield penalty of $A G 1 \mathrm{QTL}$ under normal conditions. However, further evaluation, including multi-location trials, is needed to confirm the results.

In conclusion, this study shows the successful development of the improved Ciherang-Sub1+AG1 using two backcross generations and a closely-related cultivar as a source of tolerance, even with a very small $\mathrm{BC}_{1} \mathrm{~F}_{1}$ population size. This approach may be applied to other "mega varieties" especially if the NIL for a closely-related cultivar with the trait of interest is already available. In future studies, an attempt to shorten this development process may succeed using a more efficient foreground selection in the $F_{1}$ and the use of a larger $\mathrm{BC}_{1} \mathrm{~F}_{2}$ population. In addition, the $S U B 1$ and $A G 1$ QTLs could be pyramided with other mapped QTLs for tolerance to $\mathrm{AG}$ (Septiningsih et al. 2013b) or 
submergence (Septiningsih et al. 2012) to further enhance the tolerance under severe flooding stress which would likely be intensified due to climate change. A similar approach may also be used to combine these traits with tolerance to other abiotic stresses.

\section{ACKNOWLEDGMENTS}

We thank R. Garcia, J. Mendoza, J. A. Tarun, E. Suiton, M.D. Baltazar, D. Sanchez, M. Pelayo, and V. Bartolome for the technical assistance. The work reported here was supported in part by a grant from the Bill \& Melinda Gates Foundation (BMGF) through the project "Stress-Tolerant Rice for Africa and South Asia (STRASA)" and by the Global Rice Science Partnership (GRiSP).

\section{REFERENCES}

Angaji SA, Septiningsih EM, Mackill DJ, Ismail AM. 2010. QTLs associated with tolerance of flooding during germination in rice (Oryza sativa L.). Euphytica 172: 159-168.

Ashikari M, Matsuoka M. 2006. Identification, isolation and pyramiding of quantitative trait loci for rice breeding. Trends Plant Sci. 11(7): 344-350.

Baltazar MD, Ignacio JCI, Thomson MJ, Ismail AM, Mendioro MS, Septiningsih EM. 2014. QTL mapping for tolerance of anaerobic germination from IR64 and the aus landrace Nanhi using SNP genotyping. Euphytica 197: 251-260

Collard BCY, Mackill DJ. 2008. Marker-assisted selection: An approach for precision plant breeding in the twenty-first century. Philos. Trans. R. Soc. Lond. B Biol. Sci. 17: 1-16.

Food and Agriculture Organization of the United Nations. 2009. How to feed the world in 2050. Retrieved from the high level expert forum, issues brief (2009). Rome, Italy. URL http://www.fao.org/fileadmin/templates/wsfs /docs/expert_paper/How_to_Feed_the_World_in_20 50.pdf. Accessed October 2013.

Iftekharuddaula KM, Newaz MA, Salam MA, Ahmed HU, Mahbub MAA, Septiningsih EM, Collard BCY, Sanchez
DL, Pamplona AM, Mackill DJ. 2011. Rapid and high-precision marker assisted backcrossing to introgress the SUB1 QTL into BR11, the rainfed lowland rice mega variety of Bangladesh. Euphytica 178: 83-97.

International Rice Information System. 2009. URL http:// irri.org/tools-and-databases/international-rice-inform ation-system. Accessed October 2010.

Ismail AM, Thomson MJ, Vergara GV, Rahman MA, Singh RK, Gregorio GB, Mackill DJ. 2010. Designing resilient rice varieties for coastal deltas using modern breeding tools, p. 154-165. In: C. T. Hoanh, B. Szuster, K. S. Pheng, A. Nobel, A. M. Ismail (eds.). Tropical Deltas and Coastal Zones: Food production, communities and environment at the land-water interface. CAB International, UK.

Jackson MB, Ram PC. 2003. Physiological and molecular basis of susceptibility and tolerance of rice plants to complete submergence. Ann. Bot. 91: 227-241.

Jena KK., Mackill DJ. 2008. Molecular markers and their use in marker-assisted selection in rice. Crop Sci. 48: 12661276.

Mackill DJ. 2004. Breeding for resistance to abiotic stresses in rice: the value of QTLs. Proc. of the International Symposium on Plant Breeding, CIMMYT, Mexico (August 2003). pp. 17-22.

Mackill, DJ. 2006. Breeding for resistance to abiotic stresses in rice: the value of quantitative trait loci. p. 201-212. In: K. R. Lamkey, M. Lee (eds.). Plant breeding: the Arnel R Hallauer International Symposium. Blackwell Pub, Ames, IA.

Mackill DJ, Ismail AM, Pamplona AM, Sanchez DL, Carandang JJ, Septiningsih EM. 2010. Stress tolerant rice varieties for adaptation to a changing climate. Crop Environment and Bioinformatics 7: 250-259.

Mackill DJ, Ismail AM, Singh US, Labios RV, Paris TR. 2012. Development and rapid adoption of submergencetolerant (Sub1) rice varieties. Adv.. Agron. 115: 303-356.

Naklang K. 1997. Direct seeding for lowland rainfed rice in Thailand. p. 126-136. In: S. Fukai, M. Cooper, J. Salisbury (eds.). Breeding strategies for rainfed lowland rice in drought prone environments. Proceedings of an International Workshop, Ubon Ratchathani, Thailand, 1996. Australian Centre for International Agricultural Research, Canberra, Australia.

Naklang K, Fukai S, Nathabut K. 1996. Growth of rice 
cultivars by direct seeding and transplanting under upland and lowland conditions. Field Crops Res. 48: 115-123.

Neeraja CN, Maghirang-Rodriguez R, Pamplona A, Heuer S, Collard BCY, Septiningsih EM, Vergara GV, Sanchez D, Xu K, Ismail AM, Mackill DJ. 2007. A marker-assisted backcross approach for developing submergence-tolerant rice cultivars. Theor. Appl. Genet. 115(6): 767-776.

Pandey S, Velasco L. 2002. Economics of direct seeding in Asia: patterns of adoption and research priorities. p. 3-8. In: S. Pandey, M. Mortimer, L. Wade, K. Lopez, B. Hardy (eds.). Direct seeding: research strategies and opportunities. International Rice Research Institute, Los Baños, Philippines.

Ram PC, Singh BB, Singh AK, Ram P, Singh PN, Singh HP, Boamfa I, Harren F, Reuss J, Jackson MB, Setter TL, Wade LJ, Singh VP. 2002. Physiological basis of submergence tolerance in rainfed lowland rice: prospects of germplasm improvement through marker aided breeding. Field Crops Res. 76: 131-152.

Septiningsih EM, Collard BCY, Heuer S, Bailey-Serres J, Ismail AM, Mackill DJ. 2013a. Applying genomics tools for breeding submergence tolerance in rice. p. 9-30. In: R.K. Varshney, R. Tuberosa (eds.). Translational genomics for crop breeding: Volume 2 - Improvement for abiotic stress, quality and yield improvement. Wiley-Blackwell, USA.

Septiningsih EM, Hidayatun N, Sanchez DL, Nugraha Y, Carandang J, Pamplona AM, Collard BYC, Ismail AM, Mackill DJ. 2015. Accelerating the development of new submergence tolerant rice varieties: the case of CiherangSub1 and PSB Rc18-Sub1. Euphytica 202: 259-268.

Septiningsih EM, Ignacio JCI, Sendon PMD, Sanchez DL,
Ismail AM, Mackill DJ. 2013b. QTL mapping and confirmation for tolerance of anaerobic conditions during germination derived from the rice landrace Ma-Zhan Red. Theor. Appl. Genet. 126: 1357-1366.

Septiningsih EM, Pamplona AM, Sanchez DL, Neeraja CN, Vergara GV, Heuer S, Ismail AM, Mackill DJ. 2009. Development of submergence-tolerant rice cultivars: the Sub1 locus and beyond. Ann. Bot. 103: 151-160.

Septiningsih EM, Sanchez DL, Singh N, Sendon PMD, Pamplona AM, Heuer S, Mackill DJ. 2012. Identifying novel QTLs for submergence tolerance in rice cultivars IR72 and Madabaru. Theor. Appl. Genet. 124: 867-874.

Shinada H, Iwata N, Sato T, Fujino K. 2014. QTL pyramiding for improving of cold tolerance at fertilization stage in rice. Breed. Sci. 63(5): 483-488.

Singh S, Mackill DJ, Ismail AM. 2009. Responses of SUB1 rice introgression lines to submergence in the field: Yield and grain quality. Field Crops Res. 113: 12-23.

Sumarno UG, Sutisna E. 2010. Identification of rice (Oryza sativa $\mathrm{L}$.) varieties suitable for dry season and wet season planting. Indonesian J. Agr. Sci. 11: 24-31.

Wang P, Xing Y, Li Z, Yu S. 2012. Improving rice yield and quality by QTL pyramiding. Mol. Breed. 29: 903-913.

Widawsky D, O'Toole JC. 1990. Prioritizing the Rice Biotechnology Research Agenda for Western India. The Rockefeller Foundation, New York, USA. p. 86.

Xu K., Mackill DJ. 1996. A major locus for submergence tolerance mapped on rice chromosome 9. Mol. Breed. 2: 219-224.

Zheng K., Subudhi PK, Domingo J, Magpantay G, Huang N. 1995. Rapid DNA isolation for marker assisted selection in rice breeding. Rice Genet. Newsl. 12: 255-258. 